\title{
Assessment of Patient and Relatives Satisfaction in a Cardiac Surgery ICU Model
}

Kamran Shadvar ${ }^{1}$, Ata Mahmoodpour ${ }^{2}$, Hassan Soleimanpour ${ }^{3}$, Eissa Bilejani ${ }^{2}$, Bahman Naghipour ${ }^{2 *}$, Daryoush Sheikhzadeh ${ }^{2}$, Roghayyeh Shadbakhsh ${ }^{4}$

1. Cardiovascular Research Center, Tabriz University of Medical Sciences, Tabriz, Iran

2. Department of Anesthesiology, Tabriz University of Medical Sciences, Tabriz, Iran

3. Road Traffic Injury Research Center, Tabriz University of Medical Sciences, Tabriz, Iran

4. Department of Surgery, Tabriz University of Medical Sciences, Tabriz, Iran

5. Tabriz University of Medical Sciences, Tabriz, Iran

\begin{abstract}
Introduction: Evaluation of patients' and their families' satisfaction regarding the quality of care in the ICU is an important concern that can identify deficiencies of this field and help to improve satisfaction of both patients and their families. Considering the fact that problems related to cardiac surgery ICUs differ from other ICUs, recognition of these problems and the factors that lead to patient or family dissatisfaction can not only improve the quality and quantity of services provided in this section but also lead to increased satisfaction in these groups and promote scientific and practical knowledge related to sectors at regional levels. The aim of this study was to evaluate the satisfaction of patients and their families from the quantity and quality of services provided in the cardiac surgical ICU of Madani hospital, Tabriz, Iran. Materials and Methods: In this descriptive study, satisfaction of patients and their relatives from cardiac surgery ICU of Shahid Madani Hospital was evaluated using Modified MISS questionnaire for patients and CCMFNA questionnaires for their relatives during one year (1391-1390). The obtained data were statistically analyzed using descriptive statistics (frequency, percentage, mean \pm SD) and SPSS ver. 15. Results: Majority of patients expressed moderate to high satisfaction. The overall satisfaction of doctors was higher than nurses ( $27 \%$ vs. $22 \%$ ). The lowest level of satisfaction related to the possibility of meeting relatives (14.3\%). Most relatives were spouses of patients who contributed to the highest rate of satisfaction; however, the location and meets expectations were less satisfactory. Conclusion: Improving waiting room quality, increasing duration of family meetings and increasing nursing attention are the factors that could be associated with further satisfaction.
\end{abstract}

Keywords: ICU; Patient satisfaction; Family satisfaction

\section{Corresponding author:}

Bahman Naghipour

Department of Anesthesiology, Tabriz University of Medical Sciences, Tabriz, Iran

E-mail: b_naghipour@yahoo.co.uk Phone: +989143019621

Receive date: 2015-06-15| Accept date: 2015-06-29| Publish date: 2015-08-04

DOI: 10.7575/aiac.abcmed.15.03.04.05

\section{A. I}




\section{Introduction}

Survival, activity and quality of life and care are the primary measures of outcome and evaluating service satisfaction (1-2). Interest in the fields of medicine focusing on patient satisfaction has been increasing over the past half century. In 1980, the concept of quality of care was considered a major concern in monitoring and improving health care (3). Therefore, patients and their relatives' opinions were considered as important elements in assessing the quality of service (3-5). Compared to other medical centers, academic centers face special problems in terms of patient satisfaction whose identification can be helpful in improving the services provided to patients (6). On the other hand, the satisfaction degree of patients' relatives in ICU care is another important issue that should be considered (7). Patients' relatives are daily faced with conditions, equipment, and individuals that can have a great influence on their satisfaction of the quality of the care provided in ICU. Hence, the evaluation of the service quality is inevitably a major part of family satisfaction in the ICU (8-11) which can identify the existing shortcomings and in turn provide appropriate guidelines for the detection and elimination of these limitations.

Considering the fact that the problems related to cardiac surgery ICU are different, to some extents, than other intensive care units, it seems that recognizing these problems and the factors causing dissatisfaction among patients and their relatives in cardiac surgery ICU is pivotal. Such recognition could not only be used as a guideline to improve the quantity and quality of services provided in this section, but also lead to increased satisfaction in this group promoting scientific and practical knowledge.

The aim of this study was to evaluate the patients' and their families' satisfaction of cardiac surgery ICU in Madani hospital, Tabriz, Iran in 2011-2012.

\section{Materials and methods}

In this prospective study, after obtaining written informed consent and approval of the Ethics Committee of Tabriz University of Medical Sciences, 200 patients that have been admitted to cardiac surgery ICU in Madani hospital, Tabriz, Iran were studied. To evaluate the satisfaction of patients and their relatives of cardiac surgery ICU care, modified MISS (12) (for patients) and CCMFNA (for relatives) questionnaires were answered at discharge from ICU and analyzed. Inclusion criteria were: admission to the ICU during the study, having undergone cardiac surgery, ICU stay of two days or more and alert and oriented patient. Exclusion criteria were: age of less than 18 years, patient or relative refusal for entry to the study, mental illness preventing from proper completion of the questionnaires, lack of compliance to complete the questionnaire and patient death.

All data were obtained from the questionnaires, evaluated and statistically analyzed using descriptive statistics (frequency, percentage, mean \pm SD) and statistical software SPSS ver. 15.

\section{Results}

During the study period, 200 patients with the minimum and maximum ages of 19 and 86 years (57.96 \pm 13.11 years) (Figure 1 ) were enrolled. The obtained findings are as follows: 127 (63.5\%) patients were male and 73 (36.5\%) were female (Fig 2). The majority of patients were illiterate and CABG surgery was the most common surgery type (Table 1 ). The Minimum and maximum length of stay in the ICU were 3 and 20 days $(4.82 \pm 2.31)$, respectively. The minimum and maximum numbers of ICU admission were 1 and 5 times (1.46 \pm 0.96$)$, 


\begin{tabular}{lcc}
\hline & Number & Percent \\
\hline CABG & 96 & $48 \%$ \\
$\begin{array}{l}\text { Valve repair or } \\
\text { replacement }\end{array}$ & 62 & $31 \%$ \\
$\begin{array}{l}\text { CABG + Valve } \\
\text { replacement }\end{array}$ & 33 & $16.5 \%$ \\
Other operations & 9 & $4.5 \%$ \\
\hline
\end{tabular}

Table 1: Types of surgery

respectively. In the point of demographic features of the relatives, the minimum and maximum age were 19 and 72 years (40.29 \pm 12.78), respectively; 96 people (48.0\%) were males and 104 people (52.0\%) female (Table 2). There was no significant association between age and sex of patients and their satisfaction with the ICU care, $(P=0.269, R=0.081)$ and $(P=0.915, \quad R=0.635)$, respectively. Patient satisfaction was significantly higher with $C A B G$ surgery than other surgeries $(P=0.032)$. Patient satisfaction with the type of surgery decreased as the level of education increased $(P=0.001$, $\mathrm{R}=-0.53$ ).

\begin{tabular}{lcc}
\hline & Number & Percent \\
\hline Age & $40.29 \pm 12.78$ & - \\
Male & 96 & $48 \%$ \\
Female & 104 & $52 \%$ \\
Illiterate & 33 & $16.5 \%$ \\
Primary school & 100 & $50 \%$ \\
Secondary school & 42 & $21 \%$ \\
Advanced & 19 & $9.5 \%$ \\
Diploma & & \\
Bachelor's degree & 6 & $3 \%$ \\
or higher & & \\
Spouse & 66 & $33 \%$ \\
Father & 32 & $16 \%$ \\
Mother & 21 & $10.5 \%$ \\
Brother & 14 & $7 \%$ \\
Sister & 34 & $17 \%$ \\
Daughter & 21 & $10.5 \%$ \\
Son & 12 & $6 \%$ \\
\hline
\end{tabular}

Table 2: Demographic characteristics of the patients' families

\section{Discussion}

Interest in the field of patient satisfaction has been broadly studied over the past half century. In 1980, the concept of quality of care was a major issue in monitoring and improving health care (3). Therefore, patient satisfaction is considered as an important issue in evaluating the quality of service (3). Compared to other medical centers, university hospitals have specific problems regarding patient satisfaction whose detection can be helpful in improving the services provided for the patients (6). On the other hand, relatives' degree of satisfaction with the ICU care was another important issue that must be considered (7). Relatives of the patients are faced with the condition, equipment and individuals that can influence immensely their satisfaction with the quality of ICU care. Therefore, family satisfaction in the ICU is also another part of the evaluation of quality of service $(8,13,14)$. Patient satisfaction and quality of nursing care are related to each other in long term; the issue of patient satisfaction and its relevance with nursing care is of particular importance in this regard. However, ICU patients are generally more ill and require further attention. Several studies have shown that patients are generally satisfied with the way nursing care is provided $(4,13,15)$.

In various studies, including a study that was conducted in the Emergency Department of Imam Reza Hospital, Tabriz, Iran, it was concluded that to attract patient satisfaction great attention must be paid on the need for medical care, nurse care, hospital personnel behavior, waiting time and the duration of providing services (4). In our study, behavior of the staff and their intimacy, physician satisfaction, information and explanations to patients with staff, pain treatment, and ability to meet with relatives' satisfaction were achieved in $72 \%, 80.7 \%, 60.2 \%, 70.4 \%$ and $43 \%$ of the patients, respectively. This suggests that relatives have lower levels of satisfaction which might be due to stricter policies of ICU 
management to prevent transmission of infection to other patients.

In our study, patient age ranged from 19 to 86 years $(57.96 \pm 13.11)$ and the mean duration of hospitalization in the ICU was $4.82 \pm 2.31$ days. The level of education among the studied patients was as follows: 67 patients (5.33\%) were illiterate, 51 (5.25\%) primary education, 32 (16\%) primary school, 34 (17\%) high school or diploma, $9(5.4 \%)$ of associate degree and 7 (5.3\%) had bachelor or higher degrees.

In a study performed by Tervo-Heikkimen et al., patients age ranged from 18 to 95 years old; $57 \%$ of patients had primary education, 33\% secondary and $10 \%$ were university graduates. $20 \%$ of patients stayed in the ICU for 1 to 2 days, $44 \%$ for 3 to 6 days and 25\% for 1 to 2 weeks (16). There was a relative agreement between data and demographic data of our study and this study. In our study, the highest patient satisfaction was in terms of medical attention and the most dissatisfaction was inattention of the ICU staffs to difficulties expressed by the patients which seems to be of full compliance with this study (16).

The majority of the relatives were satisfied in our study. Most complaints were the companions of the place and unmet expectations. At this point, it seems necessary to note that as there is no waiting room in the ICU of Madani hospital, most complaints were from the place for companions and unmet expectations. Patients' relatives were spouse in 66 (33\%), father in 32 (16\%), mother in 21 $(10.5 \%)$, brother in $14(7 \%)$, sister in $34(17 \%)$, daughter in 21 (10.5\%) and son in 12 (6\%) cases.

In a study conducted by Stricker and colleagues, the authors ultimately concluded that the patient spouse can be better fellows in his/her case and dealing with comment than the others. In our study, due to the higher proportion of spouses among relatives of patients, this conclusion could be argued (8).

In a study conducted by Daren and his colleagues to assess satisfaction with ICU care in a multi-center study, it was found that patients' families in general were satisfied with the service provided to his/her patient. Most of the people are satisfied with the nursing care and the lowest satisfaction was from waiting times to visit their patients (17). The results of this study which indicated that more relatives were satisfied with the nursing and medical services and the minimum satisfaction was from waiting time and place are similar to our study.

In Myles et al. study, patient satisfaction after anesthesia and surgery in 10811 patients were evaluated. In general, patients were satisfied with the provided care and dissatisfaction rate was significantly higher among male and aged patients (18). Our study showed that no significant correlation existed between age or sex of patients and their satisfaction of ICU services.

\section{Conclusion}

Patient satisfaction in most cases was moderate to high. The overall patient satisfaction from doctors was higher than nurses $(27 \%$ to $22 \%)$. The lowest level of satisfaction was related to the possibility of meeting with relatives (14.3\%). In most cases, the relatives were satisfied but because there was no waiting room, the expected relative satisfaction was lower in this field.

Further studies are required to measure patient satisfaction in other intensive care units. Considering less patient satisfaction with the handling of complaints, we recommend a brief session held for staff to pay more attention to patient complaints. To prevent the accumulation of visitors, we recommend providing waiting room for visitors. 


\section{Specific terms:}

1. Relatives: First degree relative (father, mother, sister, brother, son and wife) who were older than 18 years and had two meetings for 10 minutes with the patients.
2. Modified MISS =Modified Medical Interview Satisfaction Scale: The questionnaire was designed to assess patient satisfaction.

3. CCMFNA $=$ The Society of Critical Care Medicine's Family Needs Assessment: The questionnaire was designed to assess family satisfaction.

\section{References}

1. Stricker KH, Kimberger O, Brunner L, Rothen HU. Patient satisfaction with care in the intensive care unit: Can we rely on proxies? Acta Anesthesiol Scand 2010;8:1-8.

2. Walker JK. Patient satisfaction the best direct the way to the future. J Perinat neonat 2006;20:88-90.

3. Latour JM, Altazelzet JanA, Heijden V, Albert J. Patient satisfaction in pediatric intensive care: a critical appraisal of the literature. Pediatr Crit Care Med 2005;6:578-84.

4. Soleimanpour H, Gholipouri C, Salarilak S, Raoufi P, Vahidi RG, Jafari Rouhi A, et al. Emergency department patient satisfaction survey in Imam Reza Hospital, Tabriz, Iran. International Journal of Emergency Medicine 2011;4(2): 1-7.

5. Soleimanpour H, Tabrizi JS, Farnam A, Nikakhtar M, Mokhtarpour M, Golzari SE, et al. Attitudes of emergency medicine physicians towards family presence during resuscitation. Resuscitation 2013; 84:e149-e150.

6. Press I. The academic medical center and patient satisfaction. Q Manage Health Care 2008;17:275-79.

7. Serra Neves FBC, Dantas MP, Bitencourt AGU, Sena Vieia P, Magalhaes LT, MeiratelesJM, et al. Analysis of family satisfaction in intensive care unit. Rev Braster Intensiva 2009;21(1):32-37.

8. Stricker KH, Kimberger O, Schmidlin K, Zwahlen M, Mohr U, Rothen HU. Family satisfaction in the intensive care unit: what make the differences. Intensive Care Med 2009;35:2051-59.

9. Stricker KH, Niemam S, Bugnon S, wurz J, Rohrer O, Rothen HU. Family satisfaction in the intensive care unit: Cross cultural adaptation of a questionnaire. journal Of Critical Care 2007;22:204-11.

10. Wall RJ, Engelberg RA, Downey L, Heyland DK, Cortis JR. Refinement, scoring, and validation of the family satisfaction in the intensive care unit( Fs - ICU) survey .Crit Care Med 2007;35(1):271-79.

11. Quintana JM, Gonzalez N, Bilboo A, Aizpuru F, Escobar A, Esteban C, et al. Predictors of patient satisfaction with hospital health care. BMC Health Services Research 2006;6:102

12. Meakin R, Weinman J. The medical interview satisfaction scale (MISS-14. adapted from british general practice. Family Practice - an International Journal 2002;19(3):257-63.

13. Damghi N, Khadri I, Oualili L, Abidi K, Madani N, Zeggwash AA, et al. Measuring the satisfaction of intensive care unit patient families in morocco: A regression Tree analysis. Crit Care Med 2008;36(7): 2084-91.

14. HeylandDK, Rocker GM, Dodek PM, Kutsogiamis DJ, Kenopad E, Cook DJ, et al. Family satisfaction with care in the intensive care unit : Results of a multiple center study. Crit Care Med 2002;30(7): 1413-18.

15. Al-mailam FF. The effect of nursing care on overall patient satisfaction and its predictive value on return to provider behavior. Asurvey study. Q Manage Health Care 2005;14(2):116-120.

16. Tervo-Heikkimen $T$, Kuist $T$, Partanen $P$, Vehvilainen-julkunen $K$, Aalto $P$. Patient satisfaction as a positive nursing outcome. J Nurs Care Qual 2008;23(1):58-65. 
17. Heyland D,et al. Family satisfaction with care in the intensive care unit: Results of a multiple center study. Critical Care Medicine 2002;30(7):1413-1414.

18. Myles P S, Williams D L,Hendrata M,Anderson H,Weeks $M$. Patient satisfaction after anaesthasia and surgery: results of a prospective survey of 10811 patients. British Journal of Anaesthasia 2000;84(1):6-10. 